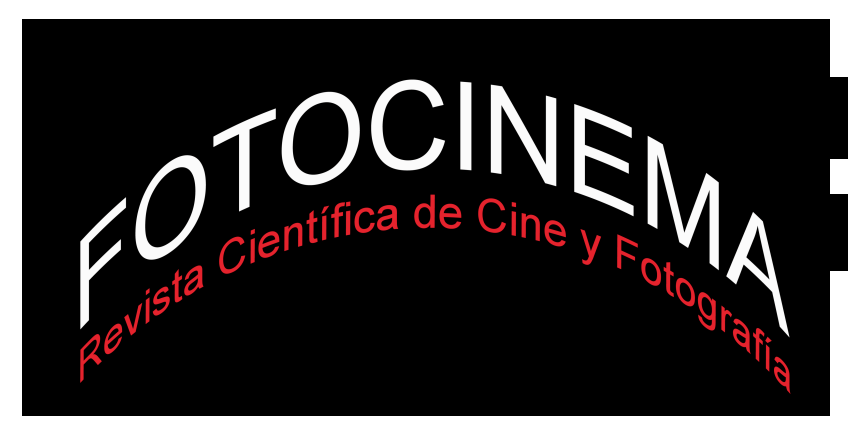

\title{
LA REVUELTA TEMPORAL COMO MÉTODO DE LA VANGUARDIA DE ENTREGUERRAS
}

\section{TEMPORAL REBELLION AS AVANT-GARDE CINEMA METHOD}

\author{
$M^{a}$ Soliña Barreiro \\ ESUPT-UPF, España \\ msolinabarreiro@gmail.com
}

\section{Resumen:}

El cine de vanguardia es un medio privilegiado para estudiar la experiencia temporal moderna porque es un complejo compendio de tiempos $y$ discontinuidades. $\mathrm{Y}$ a su vez, la temporalidad es clave para definir $\mathrm{y}$ estudiar la vanguardia cinematográfica. En ella se unen el interés por la exploración del movimiento, los experimentos con la imagen, la desafección narrativa y la afección por lo real. Propone también la subversión del campo fílmico (y, por veces, social).

Los cineastas de vanguardia no construían un discurso temporal alternativo pero sí se dotaban de un cuerpo coherente de revuelta basado en la exploración de esas temporalidades diversas. Trataron también de establecer la imagen como método, de deconstruir la racionalización instrumental del dominio visual $\mathrm{y}$ propusieron que de la variedad de discursos temporales en convivencia emanaba una nueva forma de historia y de imagen. Este artículo es un ensayo sobre el método de análisis de la temporalidad en la vanguardia.

\begin{abstract}
:
Avant-garde cinema is a privileged means to study the modern time experience because it is a complex compendium of times and discontinuities. At the same time, the temporality is a key element to define and study the 20's cinematographic avant-garde. This cinema is characterized by the exploration of movement, the experiments with the image, its lack of interest in narrativity and its interest on the real. It also proposes a subversion of the filmic field (and sometimes, also the social field).

Avant-garde filmmakers did not construct an alternative temporal discourse but they organized a coherent uprising corpus based on the exploration of those diverse temporalities. They established the image as a method, the deconstruction of the instrumental rationalization of the visual dominion and they proposed that a new type of history and image emanates from the coexistence of the variety of temporal discourses.

This paper is an essay on methods to study avant-garde temporality.
\end{abstract}

\section{Palabras clave:}

Cine de vanguardia; temporalidad; años 20; entreguerras; Benjamin.

\section{Keywords:}

Avant-garde Cinema; Time; 20’s; Interwar Period; Benjamin. 


\section{La revuelta temporal como método de la vanguardia de entreguerras}

¿No se obtendría una película apasionante a partir del plano de París, del desarrollo cronológico de sus distintas imágenes, de condensar el movimiento de calles, bulevares, pasajes y plazas durante un siglo en un espacio de tiempo de media hora? ¿y qué otra cosa hace el flâneur? (Benjamin, 2005, p. 120).

Benjamin reflexionaba sobre cómo una película podría condensar su trabajo mientras escribía sus notas para el Libro de los Pasajes, mostrando en esta reflexión su aprehensión de la potencialidad del cine para jugar con el tiempo y mostrarnos la historia concentrada en un movimiento. Cada película de vanguardia nos presenta en su movimiento un destello de vida moderna atrapada y comprimida en sus fotogramas. Y cada cineasta de vanguardia puede ser visto como un flâneur camarógrafo, atrapando los movimientos de la ciudad.

Los cambios que la Modernidad introdujo en todos los ámbitos de la vida y de la percepción resultan legibles a través del análisis de las manifestaciones culturales de la época y, más aún, en ese intenso lapso de entreguerras. El marco teórico de la Teoría Crítica nos permite conocer la producción material y cultural de la modernidad y analizar el funcionamiento de los objetos de consumo en la conformación de la conciencia de la sociedad. En el cine de vanguardia se pueden leer las transformaciones del tiempo en la modernidad de una manera privilegiada porque, por una parte, refleja el choque de la modernidad en la conciencia del habitante urbano al haber sido producido en esa época. Y porque, por otra parte, realiza también una reflexión crítica, consciente, a modo de discurso visual, que traslada al público por medio de una expresión estéticamente intensificada. Pero el cine de vanguardia es además el medio privilegiado para analizar la transformación de la percepción temporal moderna por su naturaleza: es el medio del movimiento y del tiempo, es un medio moderno por su origen y por sus características, es un medio mecánico y reproductible técnicamente, un medio de masas, un medio que revoluciona el ocio y la cultura visual de la modernidad. 
El reflejo de los cambios temporales de la época en las películas de vanguardia aparece en parte de forma involuntaria por ser obras creadas en un momento histórico concreto pues, "el acontecer que rodea al historiador, y del que participa, quedará en el fondo de su exposición como un texto escrito en tinta mágica” (Benjamin, 2005, p. 428). La relación entre entorno y su visualización en las obras no es directa ni siempre evidente, es su expresión pero no su reflejo exacto.

Las condiciones económicas bajo las que existe la sociedad alcanzan expresión en la superestructura; es lo mismo que el que duerme con el estómago demasiado lleno: su estómago encontrará su expresión en el contenido de lo soñado, pero no su reflejo, aunque el estómago pueda condicionar "causalmente" este contenido. El colectivo expresa por lo pronto sus condiciones de vida. Ellas encuentran su expresión en los sueños, y en el despertar su interpretación (Benjamin, 2005, p. 397).

En el análisis de las películas podemos encontrar esta expresión, este reflejo no directo. Por ejemplo, L'Argent (1929, L'Herbier) presenta un movimiento continuo de cámara bajo un argumento trivial de intrigas amorosas y económicas protagonizadas por un banquero. En la película hay una cámara desatada, hipermóvil para su época, algo mareante, continuamente fluctuante e incomprensiblemente osada en relación a la vulgaridad temática. Toda esa inestabilidad visual del filme no es otra cosa que la expresión de la especulación económica capitalista que se desarrolla en la Bolsa de París, lugar donde discurre parte de la película.

El cine de vanguardia es, entonces, un cierto reflejo del entorno en el que fue generado. Esas imágenes guardadas en el celuloide nos permiten acceder a una autorrepresentación visual de los cambios productivos y de mentalidad de los años 20 y su puesta en forma viene dada por la época, responde tanto a las necesidades expresivas y comunicativas de su tiempo (Ledo, 2005, p. 39) como a las modificaciones tecnológicas y sociales del momento. "El tratamiento dialéctico de esta cuestión [la relación entre el contenido y la forma] no puede hacer nada con la cosa estática aislada: una obra, una novela, un libro. Necesita insertarla en el conjunto vivo de las relaciones sociales" (Benjamin, 2004, p. 23). 
El cine hace de su forma y de su contenido dos elementos indisociables porque en la modernidad "la tecnología forma parte de la expresión y de la función”(Ledo, 2005, p. 23). Los recursos formales que emplea el cine de vanguardia revelan una pulsión por trasmitir la modificación de las vivencias temporales, espaciales y, en general, perceptivas: la aceleración y el ralentí de la velocidad de las imágenes, el tiempo reversible, las superposiciones, las vistas caleidoscópicas, los primeros primerísimos planos que generan extrañamiento, las vistas aéreas o las tomas desde un tren, un tranvía o un automóvil, que deforman la imagen como producto de la velocidad para expresar esta nueva experiencia, el montaje y sus reorganizaciones del sentido y los ritmos, etc. El impacto de la modernidad en la percepción humana y la consciencia que de este impacto tenían los cineastas de vanguardia determina la estética, la temática y la función de su cine. $\mathrm{Al}$ poner en forma el bruto de lo real, los cineastas le confieren gran parte de su carácter discursivo y lo vinculan irremediablemente a su época. "Reconfigurar la imagen [mediante el montaje] tiende a realzar y no a cancelar la especificidad histórica del fragmento” (Wees en Weineichter, 2005, p. 53).

Además de reflejar de un cierto modo inconsciente la realidad que las produjo, las películas de vanguardia presentan como objetos de análisis de la experiencia moderna del tiempo una especificidad que es su vertiente reflexiva y analítica. De esta forma, al examinar el tiempo social encontramos el reflejo consciente de las experiencias modernas, porque las obras de vanguardia pretendían dar expresión a los cambios sociales y sensoriales de la época moderna. En definitiva, este objeto de consumo posee, a mayores, un plus reflexivo que lo puede diferenciar de otras prácticas cinematográficas de la época y, por esto, su estudio permite trascender el mero tratamiento de mercancía cultural (sin obviar esta característica) y aprehenderlo también desde la perspectiva de una reflexión plástica sobre la sociedad moderna. Esa autoconsciencia de ser modernos conducía a los vanguardistas a tratar de abrir los ojos de los espectadores a la modernidad. Un poco avant lettre, en 1914, Mayakovski se maravillaba de cómo el cine podía hacer llegar lo nuevo al espectador: 
El cine sintió la pulsión de la vida contemporánea y aceleró sus febriles pulsaciones. (...) Se puede decir que toda la vida contemporánea, sus nervios latientes, la aceleración sobrehumana de su carrera, de sus rostros caleidoscópicos, su eterna aspiración a sensaciones siempre nuevas, todo eso no lo conocía nadie antes de la aparición del cinematógrafo" (Mayakovski en Albera, 2005, p. 163).

\section{La utopía fisiológica del hombre eléctrico}

La pulsión del cine vanguardista de mostrar las nuevas experiencias estéticamente intensificadas al público tiene que ver con el interés de los cineastas en las nuevas teorías perceptivas y en los avances científicos en el estudio del cerebro y la cognición. El cine soviético se enriqueció con los avances de Sechenov, Bechterev y Pavlov, muy populares en su país y reconocidos científicamente a nivel internacional. La finalidad de artistas y cineastas era contribuir eficazmente al nacimiento del hombre nuevo aplicando los nuevos conocimientos sobre el funcionamiento del cerebro a sus producciones.

La construcción del hombre nuevo en la URSS se reflejaba en el cine, en la imbricación del arte con lo cotidiano (arte urbano, producción textil, marquetería, etc.) y en otros aspectos como la lingüística y la psicotecnia o psicología del trabajo; en este último destacó Aleksej Gastev, quien desde 1918 implementó a través del Instituto del Trabajo un adiestramiento psicomotriz para los trabajadores basado en el taylorismo y la poesía futurista.

Algunos cineastas tenían formación específica en el campo perceptivo. Dziga Vértov y Abraham Room habían estudiado en el Instituto Psiconeurológico de Bechterev en Petrogrado. Abraham Room expresa claramente su intención de trasladar lo aprendido de Bechterev al cine en una entrevista concedida a la revista Close-up:

La pasión, la sensibilidad no tienen derecho por sí solas de acceso a la película y yo no me contento con registrar la simple manifestación externa de los sentimientos sino que quiero captarlos y mostrarlos tal como son en 
realidad, en la vida cotidiana (...) Aspiro a proyectar sobre la tela las profundidades del hombre para que el análisis de las sensaciones determinantes, de los pensamientos y de los actos se traduzca en imágenes luminosas. El profesor académico Bechterev, ahora fallecido, me familiarizó tiempo atrás con la ciencia de los reflejos humanos.

He consagrado algunos años al estudio del determinismo de los estados psíquicos, especialmente a la teoría de las inhibiciones de Freud, y a las manifestaciones diversas del miedo, la angustia, la tristeza y el amor. Lo que he aprendido me es muy útil actualmente para la preparación de los actores (Room, 1928, pp. 14-15).

El Instituto Psiconeurólogico Bechterev había sido fundado en 1907 basándose en la idea entonces novedosa de reunir las funciones de clínica, de centro de investigación y de establecimiento educacional. Bechterev trabajaba como psiquiatra a la vez que indagaba en el funcionamiento del cerebro. Sus investigaciones lo llevaron a describir el "reflejo asociativo", denominado por Pavlov como "reflejo condicionado". Aunque el trabajo de Pavlov y Bechterev se centraba en el mismo campo, Bechterev no se limitó a las investigaciones con individuos, su nueva disciplina, la reflexología, ampliaría sus miras a los conjuntos sociales, generando la reflexología colectiva. Bechterev pretendía alejarse de la sociología y trabajar los grupos como "entidades compuestas" (Bechterev, 2001, p. 46) que desarrollan reflejos de comportamiento colectivos condicionados y variables en función de una situación u otra. En el límite entre la ciencia decimonónica y la novedad del experimento científico en laboratorio, Bechterev buscaba alejarse de la observación subjetiva como mecanismo de conocimiento sin lograr, no obstante, desprenderse de tendencias especulativas de la ciencia premoderna.

Bechterev se había convertido en una figura importante en el ámbito científico y en el político, tanto antes como después de la Revolución implicándose en ella. Su Instituto se caracterizaba por desafiar al zarismo porque no estaba sujeto a la cuota limitativa de alumnos judíos que la administración imponía. Por este motivo, bastantes artistas y escritores soviéticos habían coincidido allí, no tanto por un interés científico sino por 
ser una de las pocas opciones de enseñanza superior para los rusos de origen judío. Allí estudiaron Room, Vértov o Kolstov. También estudió allí Asja Lascis, bolchevique y dramaturga letona que introduciría a Walter Benjamin en el marxismo y a quien éste dedica Dirección única (1928).

Su contacto con las teorías cognitivas influyó el cine de Vértov. En su prosa más futurista, el manifiesto Nosotros que Vértov escribió en el año 1919, da cuenta de su interés en la construcción del hombre nuevo y por eso propone "a través de la poesía de la máquina, vamos del ciudadano atrasado al hombre eléctrico perfecto" (Vértov, 1974, p. 154).

Reparemos en que la voz del cine-ojo, del director, aparece recurrentemente como nosotros o como yo. Sucede en sus poemas: “¿Es el cine cine?/ Nosotros dinamitamos el cine, para que el cine pueda ser visto"1. También se observa en los intertítulos de películas como La sexta parte del mundo (1926, Vértov) y en los manifiestos de Dziga Vértov. Ese nosotros/yo es una especie de demiurgo cinematográfico y perceptivo que educa al hombre; ese nosotros/yo posee un cine-ojo, un ojo superior que muestra lo que el ojo desnudo no alcanza, como vemos en la imagen de un gigantesco camarógrafo sobre la ciudad y sus habitantes de El hombre de la cámara. Para Vértov, "la incapacidad de los hombres para comportarse nos avergüenza ante las máquinas" (Vértov, 1974, p. 154), sólo el hombre nuevo, que habría aprendido asimilando las buenas facultades de las máquinas gracias al cine, sería un sujeto digno de ser filmado. La idea revelacionista del cine en su vertiente cámara-ojo la hallamos también en Moholy-Nagy o en Man Ray; en su vertiente de revelación de procesos por medio del movimiento, también defendida por Vértov, hallamos a Epstein o a Dulac. Dentro del cine de vanguardia, la teoría y praxis revelacionista más integral es la de Dziga Vértov; para él, la cámara, la velocidad de filmación y el montaje, es decir, el dispositivo en su totalidad, tienen capacidades revelacionistas y contribuyen a la creación del hombre nuevo.

${ }^{1}$ Además en este poema se hace una referencia a la neurocognición a través de Pavlov: "Dar ojos a la gente,/ para ver un perro/ con /los ojos/ de Pavlov". Dziga Vertov: "Künstlerische Visitenkarte. Artistic Calling Card (1917-1947)" en Dziga Vertov, Tode y Wurm (eds), p. 81. 
Vértov trabaja la idea del cineasta como arki-teckton o superobrero (Devaux, 1990) del sentido. A nivel iconológico hemos encontrado esta relación en un antecedente visual elaborado por el propio Vértov unos años antes. La imagen del demiurgo gigante de El hombre de la cámara (1929) encuentra su precursora en el enorme superobrero que trabaja para la construcción de una central eléctrica en El decimoprimer año (1928) y que es casi idéntico a nivel compositivo y conceptual. Este superobrero como demiurgo cognitivo que muestra el mundo y sus procesos como nunca antes los había sido visto el público está relacionado con el cine científico, en auge a finales de los años 10.

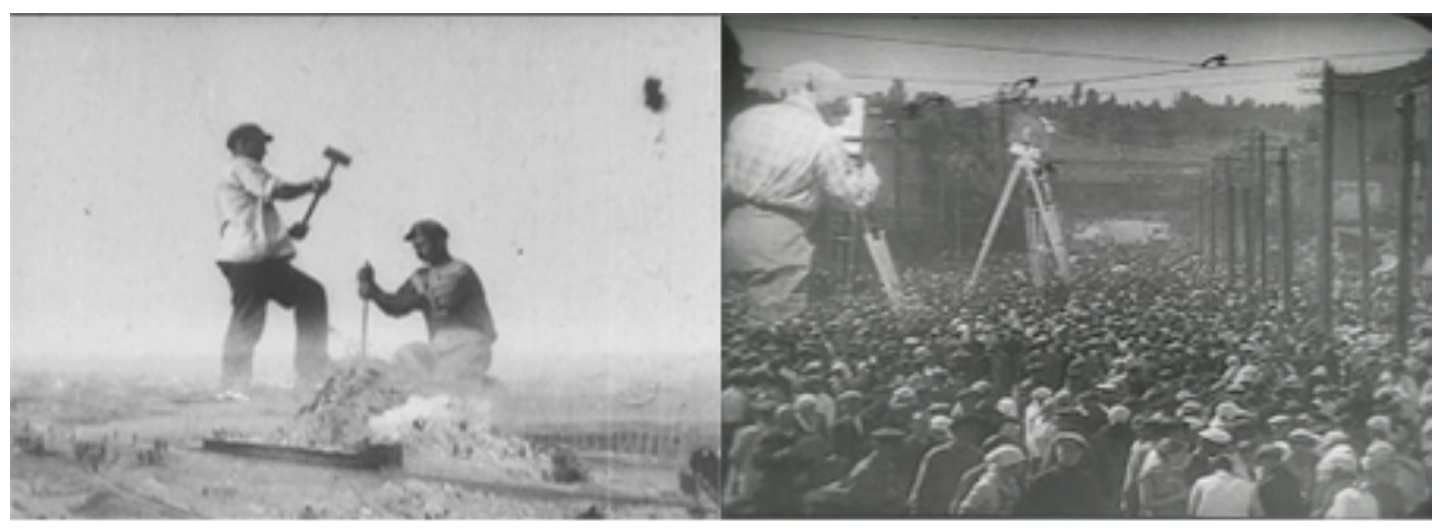

F1. Arki-tecton en El año undécimo (1928) y El hombre de Cámara (1929), de Dziga Vértov

Vértov se inscribe en esa época (1914-1916) en el Instituto Bechterev. Hay indicios de que algunos docentes del centro estaban interesados en trabajar las relaciones entre cine y cognición. El propio Bechterev publicó en 1916 un artículo en el que defendía el potencial pedagógico del cine y su utilidad para mostrar "fenómenos patológicos durante demostraciones científicas en auditorios" (Bechterev en MacKay, 2010); Bechterev se interesó también por las relaciones entre neurociencia y arte pero teniendo en mente un arte bastante convencional. Quien más trabajó la cuestión del cine y la ciencia de la percepción en el Instituto fue su vicepresidente, V.A Vagner. Vagner estaba especialmente concernido por la utilización del cine con propósitos científicos (Vagner en MacKay, 2010). En 1915 publica en el periódico Kinematograf un artículo reveladoramente titulado El papel del cine en el área de los fenómenos del movimiento. Allí asegura: 
El cine no es un simple dispositivo para representar hechos sino que dirigido por un investigador puede transformarse de un instrumento de difusión del conocimiento existente en un instrumento que facilita el descubrimiento de nuevo conocimiento que, sin su ayuda, serían inaccesibles (Vagner en MacKay, 2010).

Este fragmento nos recuerda a las palabras de Vértov “yo, máquina, muestro el mundo como sólo yo puedo verlo" (Vértov, 1974, p. 163), a la par que el título del artículo de Vagner hace referencia al estudio de los fenómenos a través de los posibles cambios en sus movimientos (ralentización, aceleración, etc.). Los filmes científicos más populares de la época se basaban en estos cambios en la velocidad de los procesos para mostrarlos más claramente: larvas que se convierten en mariposas, flores abriéndose, granos germinando, microbios actuando, etc. Las películas de Vértov contienen numerosas secuencias en las que tiempo y espacio se aceleran, se deceleran o se invierten para mostrar los procesos con la mayor claridad posible a los ciudadanos soviéticos: los procesos económicos-laborales de la producción del pan y de la carne en el Cine-ojo, el comercio internacional en La sexta parte del mundo o la mecanización del campo en Entusiasmo ${ }^{2}$; los procesos técnicos y del ocio, como la radiodifusión en el Cine-ojo o la conocida secuencia de metacine de El hombre de la cámara. También cuando su hermano y camarógrafo Mijail Kaufman trabaje en solitario utilizará el movimiento acelerado de las flores para mostrar el inicio de la primavera en Primavera (1929). Tenemos así que una herramienta técnica fundamental del cine de Vértov es la herramienta básica del cine científico de los año 10: la modificación del movimiento.

Otros cineastas como Pudovkin también se interesan por aplicar las nuevas teorías perceptivas al cine, él en concreto, trabaja sobre Pavlov. Entre 1925 y 1926 Pudovkin realiza su primera película en solitario tras dejar la química y la asistencia a Kulechov. Mecanismos del cerebro (1925-1926) explica el trabajo de Iván Pavlov y experimenta con el cine como modo de aprendizaje y mejora humana. Su idea era que la cámara funcionara a modo de ojo, como

\footnotetext{
${ }^{2}$ Si bien ni en La sexta parte del mundo ni en Entusiasmo es sólo el espacio el que se constriñe para explicar los procesos.
} 
"un reflejo condicionado preciso del ojo" (Pudovkin en Vöhringer, 2004) elemento que fue aprobado por los ayudantes de Pavlov, que harían de guionistas. Junto a esta idea de la cámara-ojo, para Pudovkin era fundamental el montaje, cuya función sería atraer y mantener la atención del espectador, para ello, debía conocer la psicofisiología y aplicarla en la mesa de montaje (Hagner, 2010). Estos dos aspectos tienen conexiones con la teoría fílmica de Vértov, como también el hecho de que Pudovkin quería que el espectador sea consciente del dispositivo fílmico. La película Mecanismos del cerebro se divide en cuatro partes y cuatro localizaciones: naturaleza, laboratorio, hospital y estudio cinematográfico. En ella presentan los experimentos de Pavlov con animales y la vida cotidiana soviética, se sigue a un bebé recién nacido que comienza a crecer en las condiciones ideales para devenir el hombre nuevo. Según Margarete Vöhringer, autora de la tesis Psychotechnik und Russische Avantgarde. Über die Konvergenz von Wissenschaft, Kunst und Technik in den Wahrnehmungsexperimenten im Russland der 1920er Jahre (2004), esta película entronca con la emergencia en el contexto artístico de la factografía y con el desarrollo en lo social de las teorías científicas para mejorar la eficiencia.

Pudovkin recordaba en 1951 la importancia de este filme en el desarrollo de su concepción cinematográfica:

Después de acabar la película, comprendí que las posibilidades de filmar acababan justo de abrirse para mí. Mi encuentro con la ciencia fortaleció mi confianza en el arte. Hoy estoy firmemente convencido de que esos dos caminos de la percepción humana están mucho más íntimamente conectados de lo que mucha gente cree (Pudovkin en Vöhringer, 2001).

Los formalistas rusos trabajaron también sobre la renovación perceptiva en la poesía e influyeron mucho en el cine de vanguardia soviético. Sklovski y Krotchnykh desarrollaron dentro de la corriente formalista las ideas de ostranenie o extrañamiento; junto a Tynianov y Eikhenbaum trataron de teorizar su aplicación al cine en Poetika Kino (Albera, 1998). Los formalistas, además teorizar, participaron en algunos proyectos cinematográficos que, en general, resultaron mucho menos radicales de lo que sí lo fue su influencia en 
otros cineastas. Sklovski fue guionista en la película de Abraham Room Cama y sofá (1927), Tinianov en El abrigo (Kozintsev y Trauberg), cuyos directores colaborarían de nuevo bajo influencia formalista para filmar la película sobre la Comuna de París Nueva Babilonia (1929), musicada por Shostakovich.

En este ambiente, el estudio de los cerebros privilegiados pronto sería un paso más dentro del intento general de mejorar al ciudadano soviético. En 1927 Vladimir Bechterev tuvo la idea de abrir un Panteón de los cerebros, partiendo del convencimiento de que el estudio de la fisionomía de los cerebros de grandes pensadores, científicos y políticos podría dar muchas claves. El recorrido del Panteón fue breve, cerró al público en 1930; y durante la década de los 30 la idea del hombre nuevo, construido por y para la nueva sociedad, aunando ciencia y arte, fue desapareciendo de las prioridades soviéticas.

El cine como herramienta de aprendizaje para habitar la sociedad moderna es una idea que aparece en otros cineastas de vanguardia no soviéticos. El húngaro Moholy-Nagy, adscrito a la escuela Bauhaus en Alemania, aseguraba que el cine debe dar "la preparación inconsciente, la educación subconsciente del hombre" (Moholy-Nagy en Vancheri, 2010, p. 76). Luc Vancheri al analizar el cine de Moholy-Nagy establece vínculos entre éste y, por una parte, las teorías perceptivas soviéticas y sus cineastas y, por otra, con la filosofía alemana y su estudio de la modernidad:

Esta hipótesis fisio-psicológica de un cine capaz de desarrollar para el hombre moderno el papel de un amortiguador visual, capaz de entrenarlo para los shocks de la vida moderna, se encuentra tanto en la teoría del cine de Eisenstein, quien la toma del neurofisiólogo Vladimir Mijailovitch Bechterev, y es ardiente defensor de las teorías de comportamentales de Pavlov, como en la filosofía estética de Walter Benjamin (Vancheri, 2010, p. 76).

Lo que sugiere Vancheri es que las teorías del reflejo condicionado, tan presentes en el contexto soviético, se extienden hasta Alemania y MoholyNagy las toma como guía para la educación de los espectadores en la vida 
moderna a través del cine. Dominique Baqué relaciona, sin embargo, las ideas de Moholy-Nagy con la influencia que la obra del biólogo Raoul Francé habría tenido en su trabajo (Baqué en Moholy-Nagy, 2005, p. 20).

El correlato filosófico que propone Vancheri lo desarrolla Benjamin, quien a caballo entre París y Berlín une la praxis fílmica de estas ciudades a través de la difusión de su teoría de la modernidad. El shock como núcleo de la experiencia moderna que trazaba Benjamin se convierte en traumatofilia (Benjamin, 2004) cuando el objetivo es conseguir el entrenamiento adecuado a través del cine para que los ciudadanos puedan manejarse hábilmente en el nuevo contexto.

La idea de emplear nuevas teorías cognitivas aplicadas a esferas diversas de la vida tiene como objetivo racionalizar los procesos, controlar su desarrollo y lograr una unidad cuerpo-mente humana como máquina para mejorar su rendimiento. El cine francés también se hallaba bajo este influjo. Para Epstein, la praxis de la fotogenia es una forma de hacer asumir al espectador la experiencia moderna, de adiestrarlo en el movimiento y en la relación con los objetos modernos para que interiorice la neurastenia por medio de la fotogenia y, así, se halle preparado para la vida moderna. Las influencias científicas en el contexto francés fueron los neurofisiólogos Lagrange, Dalcroze y Souriau, quienes trabajaban sobre la reescritura neurológica de los ritmos parar conseguir la mayor adaptación de los cuerpos al entorno.

Nina Lara Rosenblatt estudió la vinculación de este fenómeno médico-social con la estética cinematográfica, entendiendo que la adaptación al movimiento y al estrés modernos por medio del cine venían a ser una forma de "cohesión social" con la consecuente limitación del cine en su potencial de crítica violenta inherente a la teoría del shock y su traslado estético (Rosenblatt, 1998, pp. 47-62).

\section{Los tiempos de la actualización fílmica}

El empleo del cine para fomentar la mejora de la adaptación del hombre al medio y para crear el hombre nuevo se ve favorecido por la naturaleza del 
medio cinematográfico porque es un medio destinado a las masas, cuya recepción es colectiva. Su capacidad de reproductibilidad técnica amplifica la difusión de la función social de la que se dote porque sus copias son innumerables. $\mathrm{Su}$ reproductibilidad le hace también reproducir mecánicamente el entorno, reflejarlo en la pantalla, esta "vampírica relación de identidad" (Ledo, 2004, p. 26) que mantiene con la realidad le permite ejercer más fácilmente de simulacro de vida para el trabajo sobre el shock.

La reproductibilidad mecánica del cine lo emparienta con la mercancía, haciendo así que algunas características propias de ésta se trasladen al cine: una cierta fetichización y un papel de mediador entre la esfera productiva y la cultura. La vanguardia reacciona críticamente a la fetichización del cine, por esto trabaja a menudo sobre la metacinematografía y desvela los procesos de producción de su imagen. Dentro de su carácter político, de su política del arte, estos cineastas tratan de dar herramientas al público para que pueda desvelar la fantasmagoría de deseo y falsa realidad que pueden crear las imágenes si se desconoce su proceso de producción.

La reproductibilidad técnica hace a su vez entrar al cine en un dominio distinto del del arte y a los cineastas en el domino de los productores o generadores de productos culturales. Este rasgo se relaciona con la proletarización de los productores culturales de la que ya hemos hablado. La obra clave de Benjamin sobre este fenómeno es La obra de arte en la época de su reproductibilidad técnica (1936). En este opúsculo analiza las consecuencias de que las obras, mecánicamente (re)producidas, pierdan su unicidad o su aura. Estudia cómo se transforma la obra, el productor, la recepción del público y el campo de la producción artística, la función y la exhibición e, incluso, la percepción sensible.

Lo que se quiere destacar de esta obra y que se convierte en fundamental en este análisis es el concepto de actualización. La naturaleza mecánica de las obras fotográficas y fílmicas produce un trastorno profundo en la percepción del tiempo. Cada vez que el espectador presencia la obra, ésta se actualiza; a cada uso su significado y las relaciones que establece con el momento del visionado se actualizan, incluyendo nociones de pasado, de presente y de 
futuro en un mismo momento de lectura. De este modo, la imagen adquiere intensos sedimentos y proyecciones que potencian nuevos significados para el presente.

La técnica de la reproducción desprende al objeto reproducido del dominio de la tradición. Multiplicando sus ejemplares, se sustituye su caso único por su existencia en serie. $\mathrm{Y}$ permitiendo a la reproducción presentarse al receptor en la situación en la que él se encuentra, se actualiza el objeto (Benjamin, 2004, p. 17).

La actualización desemboca en "una violenta sacudida de la tradición que es la contrapartida de la crisis y la regeneración actuales de la humanidad" (Benjamin, 2004, p. 17). Esto significa que la percepción del pasado y del presente quedan trastocadas. En este proceso la función del arte se transforma, y "en lugar de reposar sobre el ritual, en adelante se funda sobre otra práctica: la política” (Benjamin, 2004, p. 26). Quiere decirse que esa radical transformación temporal de la lectura que se produce en la obra mecánica, puede tener efectos en el campo social y político. Según Benjamin, el agente más poderoso en este proceso es el cine.

Con y sobre la actualización en el cine se articula el marco de estudio de este ensayo, es el paradigma estético de la historia, basado en el estudio de las constelaciones cognoscitivas de conforman los objetos culturales en sus actualizaciones. Como veremos más adelante, junto con la actualización, el otro concepto clave es lo original.

Volviendo a su base material, el cine y la fotografía, además de reproductibles, son emanaciones directas de lo real fijadas sobre película, este hecho hace que en el trabajo y la reflexión sobre su materialidad desarrollen una serie de especificidades que, de nuevo, tienen que ver con la recepción y la generación del tiempo a través de las películas.

El cine de vanguardia es especialmente consciente de este hecho y a menudo explicita su trabajo sobre la faktura para movilizar en el espectador la reflexión temporal. Además de intentar explicar y desmitificar el medio, como hemos esbozado más arriba, trata también de trascenderlo haciendo que se evidencien materialmente los fenómenos que generan el cine (y la 
foto) desde un punto de vista físico y filosófico: el estudio del movimiento, el estudio del tiempo, la reflexión sobre lo real.

Además de la actualización, la dialéctica del registro fue acentuada por los cineastas de vanguardia creando vacíos o detenciones temporales en los filmes. La detención temporal se genera por medio de secuencias metacinematográficas o de secuencias de exploración de la materialidad. Estos vacíos temporales vienen a ser una pausa en el fluir frenético de la modernidad y crean una imagen en la que el tiempo histórico se anula para dar paso a una reflexión sobre lo real y la historia. El tiempo se detiene en Paris qui dort (1923, Clair), y también lo hace el sentido de las relaciones económicas y sociales, el dinero deja de ser útil a los que no se han visto afectados por la detención, que se aburren, porque son ricos pero no pueden gastar: el sistema es inoperativo si el tiempo se ha detenido.

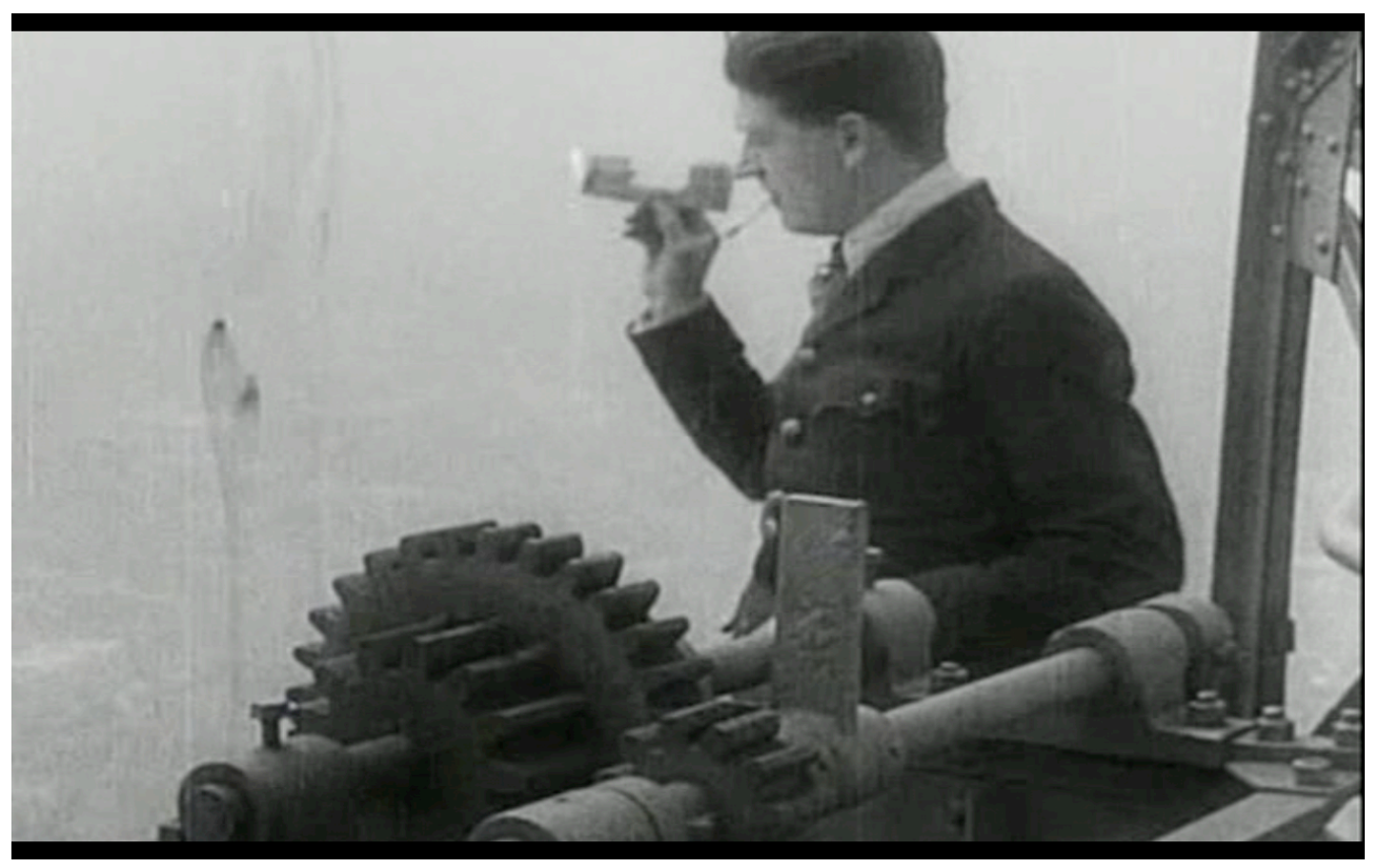

F2. Aviones de papel con billetes durante el tiempo detenido Paris qui dort (René Clair, 1923)

En su trabajo sobre lo material el cine de vanguardia experimentó con técnicas que contribuían a la desmaterialización de objetos y cuerpos para conseguir la materialización de fenómenos abstractos o invisibles como el movimiento y el tiempo. Probó también la desmaterialización de tiempos 
históricos o convencionales para materializar ritmos. La percepción de esa materialidad de la obra por el público le ayuda a descodificar el nuevo arte como antiabsoluto y antiespiritual.

El trabajo sobre la materialidad es un trabajo de reflexión sobre el tiempo. El tiempo y la materialidad están relacionados, cuando la materialidad varía lo hace también la capacidad para expresar el tiempo y la percepción del fluir. (Lawrence, 2033-2004, pp. 15.25). De ahí que un arte móvil y mecánico experimente con la materialidad para añadir recursos a sus experimentos temporales. El montaje audaz de las vanguardias contribuye también a renovar las relaciones temporales en las películas. Combinando el trabajo sobre lo material y el tiempo, los cineastas de vanguardia crearon espacios de detención temporal, de aceleración, de superposición de tiempos y generaron también de un tipo de imágenes que son cristalizaciones históricas del tiempo, esto es, huellas.

Esta huella materializada es el símbolo de una lucha por el registro permanente de lo real, de la historia, del movimiento a pesar del paso del tiempo: es un trabajo sobre la memoria activa. Esas huellas son grietas por las que se escurre una luz que permite hacer legibles para el espectador las contradicciones históricas de la sociedad moderna. El registro puede haber sido generado de forma consciente, como el contraste obsceno entre la opulencia de los burgueses y la miseria de la gente durante el carnaval en $\grave{A}$ propos de Nice (1930). O puede presentar significados distintos a la intención original, en este caso, las imágenes del trabajo son las que más se prestan a ello; a modo de ejemplo citaremos la angustia de ver a los trabajadores metalúrgicos en Komsomol (1933, Joris Ivens) hacer jornadas también nocturnas para poder construir un segundo horno de fundición del acero, cuando estas imágenes estaban pensadas para transmitir la épica del trabajo y no su angustia. También podemos observar este fenómeno en los rostros de los actores del ciclo bretón de Jean Epstein, la cara y las manos de estos pescadores revelan la fatiga, el trabajo y la vida difícil, rompen su papel ficcional y presentan con toda su crudeza el maltrato físico del trabajo. 


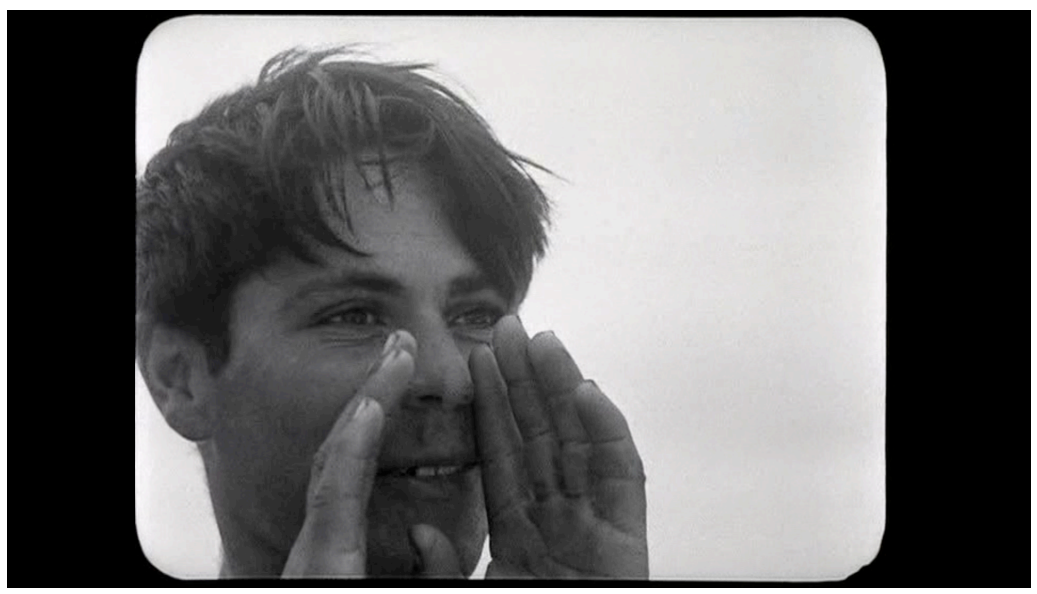

F3. Las manos del trabajo como fisura de lo real atraviesan en la ficción, Finis Terrae (Jean Epstein, 1929)

Para que en la huella se active esta carga dialéctica ha de operar la actualización y nutrirla con los nuevos significados que aporta la fractura temporal. Así, por una parte, la huella puede ser la muestra del registro (metacine) y, por otra, es un inconsciente óptico, porque revela algo que el autor ignoraba que estuviera ahí.

Benjamin enunció el concepto del inconsciente óptico partiendo de la materialidad de la fotografía en su artículo "Pequeña historia de la fotografía (1931)”. En La obra de arte... habla de este concepto, que nunca desarrolló, como aquella capacidad revelacionista del cine de mostrar lo oculto al ojo por medio del primer plano que "ensancha el espacio y el ralentí el movimiento". (Benjamin, 2004, p. 61). Nosotros lo recogemos para trabajar sobre el cine de vanguardia porque resulta útil para entender algunas fracturas temporales que nos propone.

El inconsciente óptico es la reflexión que en el espectador moviliza la fosilización del tiempo en una imagen cuando ésta tiene la capacidad de activar el pasado en el presente, esto es, produzca una relectura del pasado en función de las vivencias posteriores a la toma de esa imagen. El tiempo intermedio se fractura en este pensamiento, uniendo pasado con presente, y la imagen adquiere capacidad dialéctica, permitiéndonos descifrar elementos ocultos en el proceso histórico que se desvelan a la luz de esa aparición del presente en el pasado y viceversa. El tiempo que en ellas se fija es el activo 
dialéctico principal, amplificado por la reproducción mecánica de la imagen fílmica y asistido por su condición de mercancía. Así, estas imágenes reflejan la nueva y exultante sociedad pero a su vez abren grietas por las que se escurren las contradicciones históricas de ésta hasta hacerlas legibles para el espectador. Esta fosilización activa del tiempo se ha llamado inconsciente óptico. De nuevo la fractura temporal, que también permite la actualización de la imagen, es clave en este proceso.

Es debido a todos estos aspectos que la vanguardia mantiene unas relaciones especiales con lo real. Esta relación es más amplia y rica que de lo que implicaría el término documental. El trabajo sobre lo real abarca presente, pasado, futuro, tiempos detenidos, construidos, soñados, dislocados. El trabajo sobre lo real en el cine de vanguardia es muy diverso y original: se mezcla ficción y documento para destacar la naturaleza real de las tomas; se realizan filmaciones al imprevisto de la vida cotidiana; se experimenta con lo real de tipo material, como los haluros de plata y la luz, que genera la imagen en el inicio de Emak-Bakia (Man Ray, 1926); y se llega incluso a crear imágenes sin mediación de la cámara, imágenes por contacto directo del objeto con la película.

Esta afección por lo real tiene implicaciones políticas claras que van desde la desfetichización del medio en sí hasta la desfetichización de la "historia" que aparece en la pantalla. De esta forma, Dziga Vértov clamaba:

El cinedrama es el opio del pueblo (...) el cinedrama y la religión son armas mortales en manos del capitalismo (...) iMueran las fábulas-guiones burguesas! iViva la vida tal como es! (Vértov, 1974, pp. 215-216).

Y más explícitamente contra el fetichismo, decía en un texto titulado "Conciencia o subconciencia":

Estamos en contra de la relación entre el "director brujo" y el público embrujado (...) iMuera la cortina perfumada de besos, crímenes, palomas y trucos de prestidigitador"/iViva la visión de clase!/ iViva el cine-ojo! (Vértov, 1974, p. 211).

En la imagen de vanguardia se agolpan muchos tiempos diversos: el de la toma, el de las experimentaciones técnicas y de montaje, el del visionado y 
sus actualizaciones (huella, inconsciente óptico). Estos choques crean nuevos discursos al margen de la temporalidad lineal; son susceptibles de generar una imagen dialéctica. En la imagen dialéctica comparecen en una constelación el pretérito con el presente. Esta imagen, según Benjamin, “relampaguea en la hora de la cognoscibilidad" (Benjamin, 2005, p. 475), quiere esto decir que en un instante breve, se produce un choque que sacudiría al espectador y lo haría salir de su ensueño para que actualizara, ya en la vigilia, las imágenes de su mundo de ensueño. Las fracturas temporales de dicha imagen son lo que permite conocer el proceso económico o histórico que alumbró esa configuración visual y, tras esta iluminación, podría, quizás, prender la llama de la transformación. Al hacer estallar el continuum histórico se descubre la falsedad de la historia como progreso indetenible y se abren las vías a nuevas construcciones mentales y prácticas. De este modo se pueden diferenciar tres niveles en el proceso perceptivo de la imagen: choque, iluminación, praxis. De aquí la importancia para la vanguardia de la praxis de shock en el cine. El propio Benjamin en La obra de arte en la época de su reproductibilidad técnica había advertido de que el shock era propio del cine y había hecho avanzar esa práctica iniciada por el dadaísmo (Benjamin, 2004, p. 69). He aquí una descripción del proceso en la que, además del choque y la comparecencia temporal, se habla, al final del todo, de la anticipación, esto es, del futuro anunciado en el pasado:

Como un eco cuya resonancia que despierta parece tener lugar un día en la oscuridad de la vida transcurrida: y además, a esto corresponde el hecho de que el choque con el cual un instante penetra en nuestra conciencia como algo ya vivido, la mayor parte del tiempo nos golpea bajo la forma de un sonido. Es una palabra, un murmullo, un golpe sordo que tiene el poder de llamarnos de improviso desde la tumba glacial de "un día que", bajo la bóveda en la cual el presente parece resonar como un simple eco. Extraño que nadie se haya ocupado todavía de la réplica de este alejamiento -el choque por el cual una palabra nos hace tropezar como si fuera un aparejo olvidado en nuestra cámara oscura. Así como también, el que este eco sea algo que nos conduce a lo extraño que estaba aquí desde antes, pues hay palabras o silencios que nos llevan hacia esta extrañeza invisible: lo que el porvenir olvidó entre nosotros (Benjamin en Echeverría, 2005, pp. 113-114). 


\section{Más allá de la historicidad: lo original}

Todos esos estados temporalmente distintos que convergen en el cine de vanguardia describen la heterogeneidad temporal moderna y abren nuevas vías de pensamiento del presente y de la historia. Pero el cine de vanguardia no se agota en su historicidad, todos sus tiempos se agolpan en la idea que en él subyace, constituyendo lo original. Lo original es el anclaje que lo hace superar la simple historicidad para enfrentarlo a otros tiempos:

La experiencia de lo original, como se ofrece por excelencia en la percepción estética, se abre a una aprehensión totalmente específica de la temporalidad. Esta última se nos presenta, por así decirlo, simultáneamente, en la dimensión del pasado y en la del futuro, lo que quiere decir que ni una ni otra existen al margen de la experiencia presente, la que estamos teniendo en este momento (Mosès, 1997, p. 116).

Benjamin en El origen del drama barroco alemán opera un cambio de paradigma, pasa del paradigma estético del conocimiento al paradigma estético de la historia. Efectúa este tránsito a través del concepto de lo original, esto es, la encarnación de una idea en una obra estética, una idea que puede haber aparecido antes, en otras configuraciones, pero que alcanza su plenitud en un momento determinado. Se caracteriza por su singularidad y su repetición:

En cada fenómeno relacionado con el origen se determina la figura mediante la cual una idea no deja de enfrentarse al mundo histórico hasta que alcanza su plenitud en la totalidad de su historia. Por consiguiente, el origen no se pone de relieve en la evidencia fáctica, sino que concierne a su prehistoria y a su posthistoria. Las directrices de la contemplación filosófica están trazadas en la dialéctica inherente al origen, la cual revela cómo la singularidad y la repetición se condicionan recíprocamente en todo lo que tiene un carácter esencial (Benjamin, 1990, p.29).

Lo original combina la novedad y la antigüedad, es una idea que parece existir desde siempre pero que se percibe como algo absolutamente nuevo. Es un descubrimiento y un redescubrimiento a la vez. Esta idea supone que no hay acumulación de conocimiento, sino anamnesis o reminiscencia. 
"Carácter absolutamente nuevo e inmemorial. Esta paradoja traduce al orden de la experiencia temporal la dualidad inherente en toda idea: pertenece al mundo de la verdad, pero sólo es uno de sus fragmentos”. (Mosès, 1997, p. 115).

La pluralidad de obras de arte conforman una constelación de conocimiento, cada una con su inteligibilidad histórica propia y con sus propios tiempos. Estas obras forman en conjunto una "historia policéntrica" (Mosès, 1997, pag. 106), por ello, "alrededor de la multiplicidad de los fenómenos originales se forman, como galaxias diferentes, historias separadas, autónomas y no totalizables" (Mosès, 1997, p. 117).

El paradigma estético de la historia cuestiona, según Stéphane Mosès, los postulados de base del historicismo, es decir, la continuidad del tiempo histórico, la causalidad tradicional. Por ello, la visión estética de la historia trabaja partiendo "del presente como instancia de representación [y] se abre retrospectivamente la dimensión del pasado" (Mosès, 1997, pag.106). El futuro es retrospectivo también según esta visión porque el único ejemplo que de él poseemos "es el de la metamorfosis del pasado a medida que se va reinterpretando" (Mosès, 1997, p. 106).

Lo original es una intuición de tipo estético, que ocupa un lugar intermedio entre el mundo de las ideas y el mundo empírico. No aparece en todos los fenómenos por igual sino en algunos fenómenos privilegiados y los "identifica como encarnaciones de una idea". Como parte de la realidad empírica es limitado y sólo una de las posibles formas de la encarnación de la idea; por ello en un futuro se reiterará. Mosès analiza el desarrollo que Benjamin hace del concepto, según él:

En el libro sobre el drama barroco, lo sensible se define ante todo como el mundo del cambio y la temporalidad. Lo original aparece pues como una epifanía de la idea bajo el signo de la temporalidad. Es decir: los fenómenos originales del conocimiento se nos ofrecen como fenómenos originales de la historia. Éstos, a su vez, se nos aparecerán como los fenómenos originales del arte (Mosès, 1997, p. 114). 
No es extraño que el paradigma estético de la historia, desarrollado al estudiar el Barroco, nos sirva para trabajar el cine vanguardia. Martin Jay al hablar del régimen ocular del Barroco nos da claves muy cercanas a las que aparecen en el análisis de la vanguardia. Respecto a su trabajo formal, se caracteriza por una "sobrecarga del sistema visual con un exceso de imágenes en una pluralidad de planos espaciales como resultado, deslumbra y distorsiona en lugar de presentar una perspectiva clara y tranquila sobre la verdad del mundo externo" (Jay, 2007, p. 44). El cine de vanguardia, en lugar de una organización cientifista y clara del discurso visual que le permitirían las nuevas técnicas, hizo patente, por medio de esas posibilidades técnicas, las zonas oscuras, las posibles visiones alternativas. Jay reflexiona sobre el juego formal barroco de la anamorfosis, esto es, de la deformación reversible de la imagen. El origen etimológico de esta palabra se halla en anan, nuevo y morfosis, imagen. Para Jay esta técnica suponía el

recordatorio de un orden visual alternativo que la solidez de su presencia no puede difuminar, así como de la vanidad de creer en la realidad duradera de la percepción terrenal. Mediante la combinación de dos órdenes visuales en un espacio con un único plano, Holbein subvirtió y descentró el sujeto unificado de la visión, concienzudamente construido por el régimen escópico dominante (Jay, 2007, p. 44).

Este ensayo afirma la utilidad del paradigma estético de la historia para el estudio de las mentalidades a través de la producción cultural. En concreto, el marco se ha reelaborado para el estudio específico de la producción cinematográfica de vanguardia europea de entreguerras con vistas a estudiar la experiencia moderna del tiempo en la gran ciudad; la idea metodológica fundamental radica en elaborar un método respetuoso histórica y estéticamente con el objeto de estudio porque sólo así podrá comprenderse en toda su extensión la carga histórica de ese objeto de consumo cultural.

El cine de vanguardia de los años 20 es pues un complejo compendio de tiempos y discontinuidades, en el que se unen la exploración del movimiento, los experimentos con la imagen, la desafección narrativa y la afección por lo real, junto con la subversión del campo fílmico (y social). Teniendo en cuenta 
sus tensiones entre la autonomía de su arte y su apego al contexto moderno, las tensiones temporales internas y materiales, las tensiones temporales temáticas o externas, se establecen una serie de categorías en las que estudiar la experiencia temporal que refleja el cine de vanguardia: tiempo reversible, tiempo dislocado, tiempo proyectado, tiempo absoluto, tiempo circular, tiempo anulado, tiempo mecanizado. $Y$ éstas se agrupan en constelaciones temporales ligadas a los tres momentos de la dialéctica temporal en el cine de vanguardia: detención, destrucción, proyección.

\section{Referencias bibliográficas}

Albera, F. (2005). L’Avant-garde au cinéma. París: A. Colin.

Bechterev, V. (2001). Collective Reflexology. New Brunswick: Transaction publishers.

Benjamin, W. (1990). El origen del drama barroco alemán. Madrid: Taurus.

Benjamin, W. (2004). L'Oeuvre d'art à l'époque de sa reproductibilité technique. Courtry: Allia.

Benjamin, W. (2005). Libro de los pasajes. Madrid: Akal.

Devaux, F. (1990). L’Homme à la camerade Dziga Vértov. Bruselas: Yellow Now.

Echeverría, B. (2005). La mirada del ángel. En torno a las Tesis sobre la historia de Walter Benjamin. México DF: Ediciones Era y Facultad de Filosodía y Letras de México UNAM.

Jay, M. (2007). Ojos abatidos: La denigración de la visión en el pensamiento francés del siglo XX. Madrid: Akal.

Ledo, M. (2004). Del Cine-ojo a Dogma 95. Paseo por el amor y la muerta del cinematógrafo documental. Barcelona: Paidós.

Ledo, M. (2005). Cine de fotógrafos. Barcelona: Gustavo Gili.

MacKay, J. (2010). Vertov Inquiries, abril, mayo Comunicación email.

Moholy-Nagy, L. (2005). Pintura, fotografía, cine. Barcelona: Gustavo Gili.

Mosès, S. (1997). El ángel de la historia: Rozenweig, Benjamin, Scholem. Madrid: Cátedra.

Pozner, V. (sd). Joué versus non-joué. La notion de "fait" dans les débats cinématographiques des années vingt en URSS. Paris.

Rosenblatt, N. (1998). "Photogenic Neurasthenia: On Mass and Medium in the 1920s." October 86, (Otoño, 1998): 47-62.

Tode, T. Wurm, B (2006) (eds). Dziga Vertov. Die Vertov-Sammlung Im 
Österreichischen Filmmuseum. The Vertov Colletion at the Austrian Film Museum. 1a ed. Vol. 1. Viena: Synema Publikationen.

Vöhringer, M. (2004). Psychotechnik Und Russische Avantgarde.Über Die Konvergenz Von Wissenschaft, Kunst Und Technik in Den Wahrnehmungsexperimenten Im Russland Der 1920er Jahre [Resume Inglés: Avantgarde and Psychotechnics.on the Convergence of Science, Art and Technology in the Russian 1920s.]. Abstract. The Experimentalization For Life. Configurations between Science, Art, and Technology (2004) http://vlp.mpiwgberlin.mpg.de/exp/voehringer/index.html (consultado 22 /12/2010).

Vancheri, L. (2010). “Terra incognita: le cinéma selon Lázslo Moholy-Nagy”. Ligeia. Peintres cineastes. 97,98,99,100 (enero-junio, 2010)

Vértov, D. (1974). Memorias de un cineasta bolchevique. Barcelona: Labor.

Cómo citar: Barreiro, MS. (2016). "La revuelta temporal como método de la vanguardia de entreguerras". Fotocinema. Revista científica de cine y fotografia, $\mathrm{n}^{0}$ 12, pp. 155-178. Disponible: http://www.revistafotocinema.com/ 